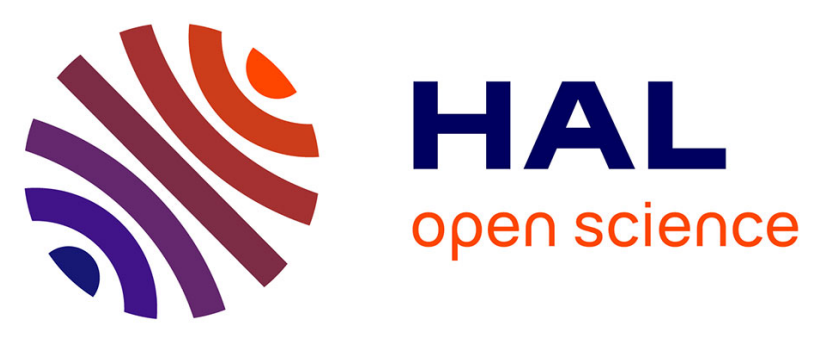

\title{
Is Openness Really Free? A Critical Analysis of Switching Costs for Industrial Internet Platforms
}

Karan Menon, Hannu Kärkkäinen, Thorsten Wuest, Timo Seppälä

\section{To cite this version:}

Karan Menon, Hannu Kärkkäinen, Thorsten Wuest, Timo Seppälä. Is Openness Really Free? A Critical Analysis of Switching Costs for Industrial Internet Platforms. 15th IFIP International Conference on Product Lifecycle Management (PLM), Jul 2018, Turin, Italy. pp.215-226, 10.1007/978-3-03001614-2_20.hal-02075609

\section{HAL Id: hal-02075609 \\ https://hal.inria.fr/hal-02075609}

Submitted on 21 Mar 2019

HAL is a multi-disciplinary open access archive for the deposit and dissemination of scientific research documents, whether they are published or not. The documents may come from teaching and research institutions in France or abroad, or from public or private research centers.
L'archive ouverte pluridisciplinaire HAL, est destinée au dépôt et à la diffusion de documents scientifiques de niveau recherche, publiés ou non, émanant des établissements d'enseignement et de recherche français ou étrangers, des laboratoires publics ou privés. 


\title{
Is Openness really free? A critical analysis of switching costs for Industrial Internet Platforms
}

\author{
Karan Menon ${ }^{1}$, Hannu Kärkkäinen ${ }^{1}$, Thorsten Wuest ${ }^{2}$ and Timo Seppälä ${ }^{3}$ \\ 1 Tampere University of Technology, Finland, \\ karan.menon@tut.fi, hannu.karkkainen@tut.fi \\ 2 West Virginia University, USA, \\ thwuest@mail. wvu .edu \\ 3 ETLA, The Research Institute of the Finnish Economy, Finland, \\ timo.seppala@etla.fi
}

\begin{abstract}
The core idea of Industrial Internet, Industry 4.0, Smart Manufacturing and Cyber Physical Systems (CPS) is to utilize Internet of Things (IoT) based technologies and applications for the purpose of enhanced operations productivity. These IoT technologies and applications help companies to integrate their business as well as their engineering, manufacturing and service processes making their operations more robust, efficient and sustainable (green) with supreme quality. Switching cost and openness of the industrial internet (II) platform has many short and long-term impacts on the end-users' business. Hence the openness is often considered to be free or synonymous to open source. The purpose of this paper is to understand and analyze the impact of II-platform's increased openness and its dimensions on switching costs framework. For empirics and to test the developed framework we conducted a training and a workshop, where 11 manufacturing and service industry representatives describe the main types of switching costs that would be impacted because of increased openness of II-platforms. As a managerial implication this new switching cost framework seem to provide a tool to evaluate the specific preferences and potential positive and negative impacts of II openness on their respective businesses.
\end{abstract}

Keywords: Industry 4.0, Industrial Internet, Smart Manufacturing, Platforms, Openness, Switching Costs, Lock-in, IIoT, IoT

\section{Introduction}

Industrial Internet or Industry 4.0 utilizes internet of things (IoT) based technologies to combine business and engineering processes improving the production efficiency, robustness as well as producing high quality products at lower costs.[1, 2] Various Industrial internet or industry 4.0 platforms allow the manufacturing companies to manage data and information efficiently in order to implement IoT related technologies to enhance their business and create value for the customers. $[3-5]$ 
Platforms and platform economy has been of increasing academic and industrial interest, both in general as well as in the specific context of industrial internet. Some common topics in platform research include, platform business models $[6,7]$, platform related network effects $[6,8]$, platform openness $[9,10]$, interoperability, lock-in [11], to name few. In the manufacturing companies' context, platform related openness is considered very important for technology implementation and creating business value.[12-14,4] This requirement from the industrial end-users also enforces platform providers to make critical decisions on platform openness. $[15,12,5]$

Industrial internet platform openness has many benefits for manufacturing companies such as, enhanced interoperability with different machines because of open standards, diverse and high end applications made by core as well as third party developers. Literature primarily discusses about the downsides or risks of platform openness from the platform supplier or provider perspective and not from the platform end-user perspective.[12,16] In our previous work we have discussed the downsides of industrial internet platform openness for platform end-users. [4] Lock-in, which is understood to be one of the long-term downside of openness, can be a result of multiple factors including increased switching costs. However relatively little is known about the impact of switching costs in a B2B context. Furthermore the impact of increased openness on switching costs is also not studied well. Hence, in this paper we apply a multi-dimensional switching cost concept together with the multi-dimensional openness concept to evaluate the impact of increased openness for manufacturing companies that use industrial internet platforms.

We have derived the following research questions to address the identified research gap related to platform openness and related switching costs especially in the context of industrial internet platforms' end-users:

RQ1 What types of switching costs would be perceived impacted by increased openness of industrial internet platforms?

RQ2 How would increased openness of industrial internet platforms impact the identified perceived switching costs?

The remainder of the paper is divided into theoretical background, research methodology and design, results and findings, discussion and conclusions.

\section{Theoretical Background}

\subsection{Industrial Internet Platforms and related trends}

Today, innovation and value creation is happening more and more digitally and online. This stands true across all industries, from marketing to manufacturing. The increasing pace of this development can be credited to some extent to the available infrastructure, on which digital offerings and applications are built upon. This development is commonly referred to as platform economy.[17] In this paper we follow the platform definition by [18], that defined industry platforms as "products, services, or technologies developed by one or more firms, 
that serve as foundations upon which a larger number of firms can build further complementary innovations and potentially generate network effects." In essence, platforms provide a structure to utilize connectivity (through the internet), analytics (computational resources) and data.

Platforms can be designed narrowly for a specific purpose or industry. However, in this paper, we focus on platforms that can be utilized on an eco-system level across different industries and/or purposes. These platforms have in common that they allow a variating degree of customization and openness towards, e.g., third party developers. Platforms in an industrial setting are often used in unison with paradigms like Industrial Internet, Industry 4.0, Internet of Things (IoT), Cyber-Physical Systems (CPS) and Smart Manufacturing. [19] argue that Industrial Internet Platforms are one of the key enabling technologies for Smart Manufacturing Systems. Industrial Internet Platforms can be used to access, store, aggregate and analyze data from a variety of sources in a manufacturing environment (e.g., machine tools, sensors, ERP or MES systems) as well as provide access to data to dedicated applications and services throughout the smart factory and beyond. One major aspect of high relevance to industrial end-users is the openness of a platform (see following chapter) and the impact on the (direct and indirect) switching costs associated with it.

\subsection{Industrial Internet Platform Openness}

From the literature, we can see that platforms are not just open or closed, they belong on a continuum between open and close.[20,14,21,22,4] Manufacturing companies need to select the right industrial internet platform in order to attain optimal openness between their customers, suppliers, sub-contractors and partners. Eisenmann et al. 2009 [23] defined that a platform is "open", as long as, 1) no restrictions are placed on participation in its development, commercialization or use; or 2) any restrictions, for example, requirements to conform with technical standards or pay licensing fees, are reasonable and non-discriminatory, that is, they are applied to all the potential platform participants. [23] This is applicable to all the actors participating in the use and propagation of the platform. These platform actors are divided into three categories; 1) Demand-side user (end-users of the platform) 2) Supply-side users (application developers in the platform) 3) Platform providers and sponsors (platform companies).[15, 18, $13,4]$

Platform openness is divided into three broader dimensions keeping the above mentioned platform actors in mind and then further divided into sub-dimensions, which results into a multi-dimensional framework for platform openness. [22, 4] The impact of industrial internet platform openness on platform providers' strategy and platform end-users' strategy has been discussed in our previous work using the same openness framework mentioned above. [22,4] 


\subsection{Platform openness and switching costs}

Some of the major effects of platform openness decisions are related to the interoperability (of platform users), network effects, as well as transaction costs and switching costs.[18, 15, 24,22] Choosing an optimal level of platform openness is crucial for companies that design and maintain the platforms (e.g. [12, $23,25]$ ), as well as companies that use those platforms [13]. In determining the level and type of openness, switching costs are one approach that can be utilized to understand especially the longer-term impacts of openness $[13,11]$.

Blut et al. [26] define switching costs as "the customer's perception of the magnitude of additional costs required to conclude the current relationship, and secure an alternative supplier." However, they state that relatively little is known about the relevance of switching costs, yet, particularly in industrial and B2B markets. Furthermore, switching costs should be seen in B2B-context as a multifaceted construct.[26] Thus, part of the novelty of this study is derived from the use of multi-dimensional switching cost concept, and reflecting the importance of platform openness from the perspective of individual switching cost components in the relatively little studied industrial B2B context, as well as the little studied perspective of industrial internet platform use, and the platform user perceptions on the impact of openness to switching costs. We present the multi-dimensional openness (see [4] for details) versus the multi-dimensional switching costs (see [26] for details) evaluation framework in Table 1.

Table 1. Platform openness [4] and switching cost framework [26]

\begin{tabular}{|c|c|c|c|c|c|c|c|c|c|c|}
\hline & \multicolumn{8}{|c|}{ Switching Costs } \\
\hline & & & \multirow{2}{*}{\begin{tabular}{|l|} 
\\
Uncertainty \\
costs
\end{tabular}} & \multicolumn{3}{|c|}{ Procedural } & & Financial & \multicolumn{2}{|c|}{ Relational } \\
\hline & & & & \begin{tabular}{|l|l|}
$\begin{array}{l}\text { Search } \\
\text { costs }\end{array}$ \\
\end{tabular} & $\begin{array}{l}\text { Training } \\
\text { costs }\end{array}$ & $\begin{array}{l}\text { Setup } \\
\text { costs }\end{array}$ & $\begin{array}{l}\text { Sunk } \\
\text { costs }\end{array}$ & $\begin{array}{l}\text { Lost performance } \\
\text { costs }\end{array}$ & \begin{tabular}{|l} 
Brand relationship \\
and psychological \\
costs
\end{tabular} & $\begin{array}{l}\text { Personal relationship } \\
\text { and psychological cost. }\end{array}$ \\
\hline \multirow{10}{*}{\begin{tabular}{|l|} 
Openness \\
Dimensions
\end{tabular}} & \multirow{3}{*}{$\begin{array}{l}\text { End-user related } \\
\text { openness }\end{array}$} & \begin{tabular}{|l|} 
Access to \\
information
\end{tabular} & & & & & & & & \\
\hline & & Cost of access & & & & & & & & \\
\hline & & \begin{tabular}{|l|} 
Control in \\
terms of rules \\
to use the \\
platform
\end{tabular} & & & & & & & & \\
\hline & \multirow{3}{*}{$\begin{array}{l}\text { Application develope } \\
\text { related openness }\end{array}$} & \begin{tabular}{|l|} 
Core \\
developers
\end{tabular} & & & & & & & & \\
\hline & & \begin{tabular}{|l} 
Extension or \\
3rd party \\
developers
\end{tabular} & & & & & & & & \\
\hline & & \begin{tabular}{|l|} 
Data \\
aggregators
\end{tabular} & & & & & & & & \\
\hline & \multirow{4}{*}{$\begin{array}{l}\text { Provider or sponsor } \\
\text { related openness }\end{array}$} & $\begin{array}{l}\text { Proprietary } \\
\text { model }\end{array}$ & & & & & & & & \\
\hline & & \begin{tabular}{|l|}
$\begin{array}{l}\text { Licensing } \\
\text { model }\end{array}$ \\
\end{tabular} & & & & & & & & \\
\hline & & $\begin{array}{l}\text { Joint venture } \\
\text { model }\end{array}$ & & & & & & & & \\
\hline & & Shared model & & & & & & & & \\
\hline
\end{tabular}

On the supplier side, significant part of management practices and tactics are often aimed at increasing switching costs, for instance through introducing loyalty schemes or offering unique customer solutions. It is rather commonly experienced that increased openness is generally something positive when viewed from the perspective of platform users: from the perspective of platform users 
and related switching costs, platform openness can e.g. allow the end users to reduce the switching cost to an alternative platform, thus allowing the end users to avoid a lock-in to the used platform ([27]).

One challenge with the proper understanding of the role of switching costs, as well as the impact of openness to switching costs is related to the nature of switching costs developing and often increasing in the course of time (see e.g. [26]). It has also been demonstrated that users have a tendency to fail to anticipate the impact of future switching costs, while having a preference of minimizing immediate costs, and thus, this leading to lock-in. Furthermore, due to common difficulty of anticipating future switching costs, as well as the manydimensionality of both openness and switching cost concepts, it may be difficult for a platform user to identify the multitude and the importance of different impacts of openness to switching costs, especially in the long run.

\section{Research Methodology and Design}

The empirical material for this paper stems from a qualitative questionnaire, training and workshop of eleven manufacturing and service companies. The material and data were collected in February, 2018. The logic of the data collection resembles that of a multiple case study.[28] Table 2 describes the industry focus and the role of the respondent in the company.

Table 2. Information on companies

\begin{tabular}{|c|c|c|}
\hline Company & Industry & Role of the respondent \\
\hline Company A & Manufacturing & Production Director \\
\hline Company B & Manufacturing & Production Manager \\
\hline Company C & Manufacturing & Production Manager \\
\hline Company D & Manufacturing & $\begin{array}{c}\text { Vice President } \\
\text { Sourcing }\end{array}$ \\
\hline Company E & Manufacturing & Production Manager \\
\hline Company F & Manufacturing & $\begin{array}{c}\text { Supply Chain } \\
\text { Project Manager }\end{array}$ \\
\hline Company G & Manufacturing & Supervisor \\
\hline Company H & Manufacturing & Program Manager \\
\hline Company I & Industrial Service & $\begin{array}{c}\text { Business Operations } \\
\text { Senior Manager }\end{array}$ \\
\hline Company J & Media Company & - \\
\hline
\end{tabular}

We collected data following methods; 1) a qualitative questionnaire was sent to the eleven participants three working days before the training and workshop. This is because we wanted to understand: a) the level of general knowledge of the participants about the platform economy and its characteristics and b) what are the platforms of industrial internet the participating companies are applying for 
their operations and services, and 2) an in-depth qualitative training and workshop was executed of the platform economy. All participants who participated the questionnaire, training and workshop work as senior operations manager positions of participating companies. Furthermore, separate discussions about the platform economy and its characteristics were conducted with the participants during the training and the workshop. In this paper we will present results only from the workshop, i.e. point 2), which focuses on the switching cost framework.

The qualitative training and workshop were conducted in a structured way: first, the participants received a three-hour introduction to the topic of platform economy and its characteristics; second, the participants received and 30min introduction to the switching cost analysis model and to its characteristics; third, the participants executed the switching cost analysis from the openness perspective as an individual task. The analysis took $60 \mathrm{~min}$ and iterative discussions were allowed to take place during the analysis between the two instructors and the participants. The data collected in training and workshops were supplemented and elaborated through the feedback collected after the training and workshop by the organizers.

During the workshop, the participants were introduced to the switching cost and openness framework, presented in Table 1. They were asked to evaluate the switching costs that would be impacted if individual sub-dimensions of openness were significantly more opened up either by their own platform or a new platform. Once they finished pointing out the switching costs, they were asked to give $\mathrm{a}+\mathrm{H}$ to the switching costs that would have a maximum impact on their business and give a reason next to every $+\mathrm{H}$ that they mark.

\section{Results and Findings}

In this section, we report the results of our initial workshop focusing on switching costs in conjuncture with our Industrial Internet Platform Openness Framework. The results are based on the data provided by ten participants with variating backgrounds regarding their companies and II platforms used. In this section, the results are strictly reported and not interpreted. An interpretation of the results and a detailed discussion with regard to the initial research question, including possible limitations of the study, is presented in the following section.

We merged the answers that the individual participants provided within the framework table depicted in Table 1 in a combined table (Table 3). This allowed us to see general patterns that emerged across the different participants feedback.

However, before describing emerging patterns, we will present general results. It is noticeable that each participant, all of them working with different platforms in their daily life, have identified multiple areas where openness relates to switching cost.

The two individual cross sections with the overall highest response count are at the intersection of the openness sub-dimension 'Access to information' and procedural switching costs category 'Setup Costs' with 10 total responses as well as 'Access to information' and 'Training Costs' with 9 total responses. 
The same ranking occurs when only counting individual 'high impact' responses, with a score of 5 for 'Access to information'/ 'Setup Costs' and 4 for 'Access to information'/'Training Costs'.

After merging the individual answers of the participants in one template, several patterns within the answers emerged. One very prominent pattern is that the openness dimension 'End-User related openness' received the most attention with a combined total of 80 selected boxes across the participants. The second openness dimension 'Application Developer related openness' is a close second in total number of 68 selected boxes. The third and final openness dimension, 'Provider or Sponsor related openness' lags behind with only 32 reported correlations. In this sense, it is also noteworthy that while all 10 participants have a minimum of 6 (dimension 1) and 3 (dimension 2) ticked boxes while a total of four participants reported no impact for dimension 3 .

Table 3. Results from the workshop

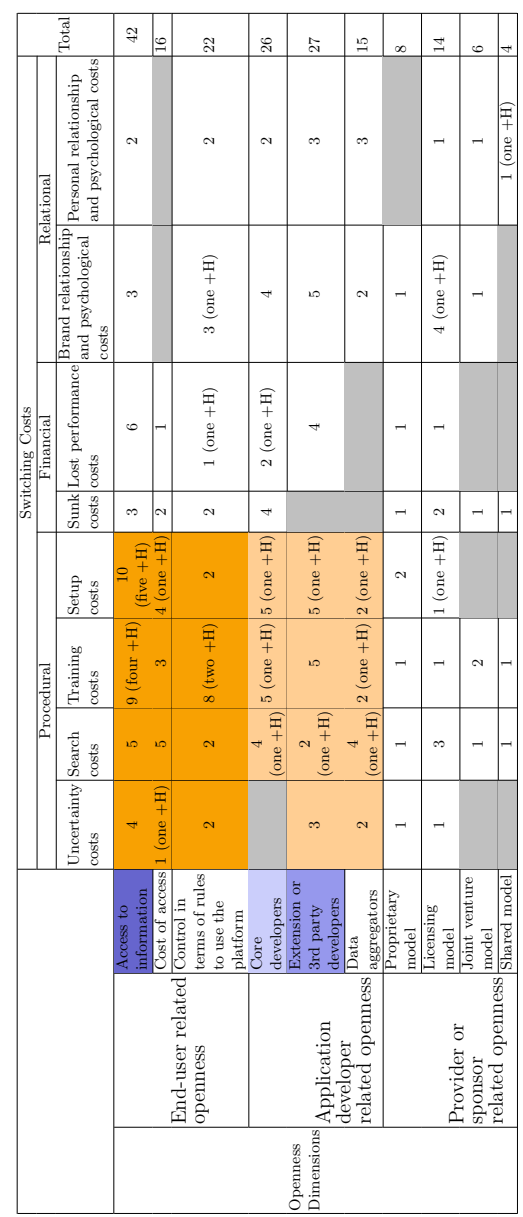




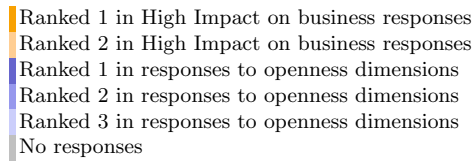

Looking closer at the openness sub-dimension level, there is a clear preference visible with the first openness sub-dimension 'Access to information' receiving a total of 42 responses with openness sub-dimensions five - 'Extension or 3rd party developers, and four - 'Core developers' accumulate 27 and 26 responses respectively. The highest score of any individual sub-dimension within openness dimension 3 is achieved by 'Licensing Model' with 14 responses, making up almost half of the total responses for this dimension.

It has to be noted that there are two intersections of between openness dimension and switching costs category standing out. Openness dimension one 'End-User related openness' and 'Procedural Switching Costs' have the most 'high impact' $+\mathrm{H}$ responses with a count of 13 . Followed by the intersection of openness dimension two 'Application Developer related openness' with the same switching cost category scoring a total of 8 'high impact' responses.

Another interesting pattern that emerging from the accumulated data is that the openness sub-dimension 'Cost of access' has no reported correlation with 'Relational Switching Cost'. Similarly, the participants reported no correlation of the openness sub-dimension 'Data aggregators' with 'Financial Switching Costs'.

The participants were asked to provide reasoning for their top-three 'high impact' cross-sections of openness related switching cost. We clustered and condensed the individual reasons to provide an overview of the reported impacts. Switching the platform to more open would mostly affect the set-up cost as well as training costs of the company. Typically, these terms set-up cost and training cost denote money and time used as an investment to benefit the company (for more information about the training costs see [29]). In our study the respondents considered that set-up cost and training cost would be quite high or high for their companies. They also considered that companies sometimes have difficulties in obtaining financial resources for such cost, especially training. Additionally, the openness of the platform would lead to even higher set-up cost and training cost.

Hence, the respondents considered that set-up cost and training cost also add value for the company (it is not always a bad thing one of the respondents said) and will lead to higher licensing revenues from the platform. They also identified new opportunities for larger indirect network effects by implementing shared revenue business models. Adding developers to the platform would lead to even larger indirect network effects (more developers make the platform better another respondent said). Furthermore, a more open platform, from the end user perspective, allow companies to get much more innovations out of it such as new data, new knowledge and new patents. However, sometimes openness might lead to higher search cost, lost performance, lost competence and for more varied systems architecture. 


\section{Discussion and Conclusions}

It can be seen from Table 3 that the overall procedural costs get impacted by increased openness of end-user related openness and application developer related openness dimensions. Procedural costs are associated with the costs that involve time and effort in searching, adopting and using a new platform as well as the uncertainty associated with the new platform. On increasing openness for end-user related dimension certain procedural costs (for example setup and training costs) increase to an extent that they have a significant impact on the platform end-user's business. This happens because the end-user manufacturing company incurs costs with respect to setting up either new servers, databases or systems related to the new platform. There is also an additional training cost associated with the features of the new platform. Similarly, increased openness for application developer related dimension also has a substantial impact on procedural costs. New applications can mean concentrated effort and investment on infrastructure as well as training the personnel on how to efficiently use these applications. Hence, it is important to understand that increased access to data, better control over the use of the platform and increase in the number of applications can increase the switching costs significantly in long term.

One of the various findings of this study was that increased openness for access to information was commonly perceived to increase the switching costs related to training and setup costs. This means access to more data and information, which can result into investments in infrastructure as well as training the personnel. None of the respondents consider increased openness towards cost of access, i.e. cost of the platform usage reduces, will impact the relational switching costs. This means that for industrial manufacturing companies it is the access to data and information that is more vital when compared to the cost of access to the platform. Another interesting finding of the study was that if the openness towards 3rd party developers would increase then some of the perceived procedural costs will have a significant impact. The is because it is the 3rd party developers or application developers, in general, that create business opportunities for the platform end-users by developing novel applications. Hence, if the openness increases for 3rd party developers then more applications will be developed on the platform motivating the end-user to stay on the platform for a long time and therefore, increasing the switching costs.

There are several limitations that need to be mentioned regarding the nature of this study and the conclusions drawn. One limitation is the size and setup of the group surveyed. While all participants have some form of experience with industrial internet platforms, they are all from different companies and serve in different roles. This might result in a bias in the answers provided. Another

limitations might be inherited in the framework itself. Given the time limit of $60 \mathrm{~min}$ for the whole exercise, the participants might spend more time on the top part of the matrix and rush through the later parts. This might have an effect on the number of responses for the different parts (higher for earlier parts, lower for later parts). The complexity of the framework itself and the explanation given 
to the participants can also be perceived as a possible limitation that should be taken into consideration when interpreting the results.

It is imperative that the managers while making an industrial internet platform selection take into consideration, not only, the benefits of openness but also the long term risks or downsides. Openness versus the switching costs framework gives an indication towards long term lock-in. It was observed in our workshop that the managers were interested to learn new kinds of costs related to switching that their company would incur if the selection is made purely based on the positives of increased openness. It is important that the managers in collaboration with different users of the platform in the company make the decision related to the impacts of openness on their business.

As part of the future studies, it would be interesting to interview multiple people from the same company, involved in platform strategy as well as platform usage related senior roles. After understanding the role of switching costs towards lock-in, it would be beneficial to understand the role of different factors, such as, network effects, transaction costs, interoperability and others.

Overall, openness in industrial internet platform brings many benefits in short and long term but understanding the long term risks such as lock-in related switching costs gives us an understanding that openness is not always "free" as it is perceived occasionally.

\section{Acknowledgement}

This work was part of funding received by Wihuri Foundation (Grant Number: 00170247) \& Välkky Project-Project Number-720118 We would like to thank our Master of Science researcher Pilar Aldama Marin for her contribution towards the study.

\section{References}

1. Wang, S., Wan, J., Li, D., Zhang, C.: Implementing Smart Factory of Industrie 4.0: An Outlook. International Journal of Distributed Sensor Networks 12(1) (jan 2016) 3159805

2. Jeschke, S., Brecher, C., Meisen, T., Özdemir, D., Eschert, T.: Industrial Internet of Things and Cyber Manufacturing Systems. Springer, Cham (2017) 3-19

3. Ehret, M., Wirtz, J.: Unlocking value from machines: business models and the industrial internet of things. Journal of Marketing Management 33(1-2) (jan 2017) $111-130$

4. Menon, K., Kärkkäinen, H., Wuest, T.: Role of openness in industrial internet platform providers' strategy. In: IFIP Advances in Information and Communication Technology. Volume 517., Springer, Cham (jul 2017) 92-105

5. Kotiranta, A., Seppälä, T., Tahvanainen, A.J., Hemminki, M., Mattila, J., Sadeoja, S., Tähtinen, T.: Roadmap for Renwal, A Shared Platform in the Food Industry. The Research Institute of the Finnish Economy (oct 2017)

6. Rochet, J.C., Tirole, J.: Two-sided markets: A progress report. In: RAND Journal of Economics. Volume 37., Blackwell Publishing Ltd (sep 2006) 645-667 
7. Hagiu, A., Wright, J.: Multi-sided platforms. International Journal of Industrial Organization 43 (nov 2015) 162-174

8. Parker, G.G., Van Alstyne, M.W.: Two-Sided Network Effects: A Theory of Information Product Design. Management Science 51(10) (oct 2005) 1494-1504

9. Gawer, A.: Platforms, markets and innovation. Edward Elgar (2009)

10. Ghazawneh, A., Henfridsson, O.: Balancing platform control and external contribution in third-party development: The boundary resources model. Information Systems Journal 23(2) (mar 2013) 173-192

11. Opara-Martins, J., Sahandi, R., Tian, F.: Critical analysis of vendor lock-in and its impact on cloud computing migration: a business perspective. Journal of Cloud Computing 5(1) (dec 2016) 4

12. Parker, G., Van Alstyne, M.: Innovation, Openness, and Platform Control. Management Science (aug 2017) mnsc.2017.2757

13. Eisenmann, T.R.: Managing Proprietary and Shared Platforms. California Management Review 50(4) (2008)

14. Benlian, A., Hilkert, D., Hess, T.: How open is this platform? The meaning and measurement of platform openness from the complementors' perspective. Journal of Information Technology 30(3) (sep 2015) 209-228

15. Parker, G.G., Van Alstyne, M.W., Choudary, S.P.: Platform Revolution: How Networked Markets Are Transformin the Economy - And How to Make Them Work for You. (2016)

16. McIntyre, D.P., Srinivasan, A.: Networks, platforms, and strategy: Emerging views and next steps. In: Strategic Management Journal. Volume 38., John Wiley \& Sons, Ltd (jan 2017) 141-160

17. Zysman, J., Kenney, M.: The Rise of the Platform Economy - Issues in Science and Technology. Issues in Science \& Technology 32(3) (2016) 61-70

18. Gawer, A., Cusumano, M.A.: Industry platforms and ecosystem innovation. Journal of Product Innovation Management 31(3) (may 2014) 417-433

19. Mittal, S., Khan, M.A., Romero, D., Wuest, T.: Smart manufacturing: Characteristics, technologies and enabling factors. Proceedings of the Institution of Mechanical Engineers, Part B: Journal of Engineering Manufacture (oct 2017) 095440541773654

20. Stefi, A., Berger, M., Hess, T.: What influences platform provider's degree of openness? - Measuring and analyzing the degree of platform openness. In: Lecture Notes in Business Information Processing. Volume 182 LNBIP., Springer, Cham (2014) 258-272

21. Hilkert, D., Benlian, A., Sarstedt, M., Hess, T.: Perceived software platform openness: the scale and its impact on developer satisfaction. In: ICIS. (2011) 1-20

22. Menon, K., Kärkkäinen, H., Gupta, J.P.: Role of Industrial Internet platforms in the management of product lifecycle related information and knowledge. IFIP Advances in Information and Communication Technology. Springer Berlin Heidelberg (jul 2016)

23. Eisenmann, T.R., Parker, G., Van Alstyne, M.: Opening Platforms: How, When and Why? In: Platforms, Markets and Innovation. (2009) 131-162

24. Henten, A.H., Windekilde, I.M.: Transaction costs and the sharing economy. info 18(1) (jan 2016) 1-15

25. Gawer, A., Cusumano, M.: Platform Leadership:How Intel, Microsoft, and Cisco Drive Industry Innovation. (2002) 305

26. Blut, M., Evanschitzky, H., Backhaus, C., Rudd, J., Marck, M.: Securing businessto-business relationships: The impact of switching costs. Industrial Marketing Management 52 (jan 2016) 82-90 
27. Matzler, K., Strobl, A., Thurner, N., Füller, J.: Switching experience, customer satisfaction, and switching costs in the ICT industry. Journal of Service Management 26(1) (mar 2015) 117-136

28. Eisenhardt, K.M.: Building Theories from Case Study Research. Academy of Management Review 14(4) (oct 1989) 532-550

29. Swanson, R.A., Cullen, J.G., Sawzin, S.A., Sisson, G.R.: Cost Effectiveness: A Model for Assessing the Training Investment. (1978) 